\title{
Vibration Attenuation of Magnetorheological Landing Gear System with Human Simulated Intelligent Control
}

\author{
X. M. Dong' and G. W. Xiong ${ }^{2}$ \\ ${ }^{1}$ State Key Laboratory of Mechanical Transmission, Chongqing University, Chongqing 400044, China \\ ${ }^{2}$ School of International Business, Sichuan International Studies University, Chongqing 400031, China \\ Correspondence should be addressed to X. M. Dong; xm_dong@126.com
}

Received 8 August 2013; Accepted 13 October 2013

Academic Editor: Sebastian Anita

Copyright (c) 2013 X. M. Dong and G. W. Xiong. This is an open access article distributed under the Creative Commons Attribution License, which permits unrestricted use, distribution, and reproduction in any medium, provided the original work is properly cited.

\begin{abstract}
Due to the short duration of impulsive impact of an aircraft during touchdown, a traditional landing gear can only achieve limited performance. In this study, a magnetorheological (MR) absorber is incorporated into a landing gear system; an intelligent control algorithm, a human simulated intelligent control (HSIC), is proposed to adaptively tune the MR absorber. First, a two degreeof-freedom (DOF) dynamic model of a landing gear system featuring an MR absorber is constructed. The control model of an MR damper is also developed. After analyzing the impact characteristic during touchdown, an HSIC is then formulated. A genetic algorithm is adopted to optimize the control parameters of HSIC. Finally, a numerical simulation is performed to validate the proposed damper and the controller considering the varieties of sink velocities and sprung masses. The simulations under different scenarios show that the landing gear system based on the MR absorber can greatly reduce the peak impact load of sprung mass within the stroke. The biggest improvement of the proposed controller is over $40 \%$ compared to that of skyhook controller. Furthermore, HSIC exhibits better adaptive ability and strong robustness than skyhook controller under various payloads and sink velocities.
\end{abstract}

\section{Introduction}

The very important design issue of landing gear systems with an adaptive ability of impact energy mitigation and simultaneous generation of minimal deceleration on the protected aircraft structure is an intensive research topic. To compass all impact scenarios (i.e., a wide range of flight parameters such as ground friction coefficient, aircraft overall weight, attitude, and sink velocity), a traditionally passive landing gear has to be employed to meet the requirement of the most heavy dynamic excitation or harsh environmental loading. As a result, it cannot avoid the highly redundant structure and trade-off performance. To attenuate the landing impact transmitted to aircraft, some active or semiactive types of landing gear systems have been suggested in aircrafts. One of the most attractive candidates to formulate an adaptive landing gear is to use magnetorheological (MR) fluid absorber because of its fast response characteristic to magnetic field, compact size, and, hence, wide control bandwidth [1-3].
The MR technology brings us salient features in alleviating the underdesirable impact load on aircrafts and pilots, on one hand. On the other hand, the significant hysteresitic nonlinearity of the MR absorbers as well as dynamic model uncertainties of the landing gear system (e.g., variable sink velocities and payloads) and especially short time impact (typically a touchdown ranging from 50 and $200 \mathrm{~ms}$ ) provides yet a significant challenge in choosing a suitable control strategy.

So far, many control methods have been investigated by many researchers in recent years through numerical simulations or simple experimental studies to deal with the challenge. There are two types of control strategies. One is that control strategy is formulated based on energy balance. For example, Mikułowski and Jankowski [4] investigated two control strategies (semiactive and active) to mitigate the peak force transferred to the aircraft structure. The semiactive control strategy is formulated based on a preset orifice area for different touchdown scenarios. Ghiringhelli 
[5] discussed the possibilities of the semiactive control of landing gears. According to the energy balance, the optimal control force is calculated. The researches [4-7] indicate that the control method based on energy balance is simple and effective and easy to understand for the single degree of landing gear system. When higher degree dynamic landing gear system or practical case is applied, the control strategy may have difficulty in calculating the energy sometimes it is even impossible considering the many uncertainties and nonlinearity in a practical landing gear system.

The other type is the nonlinear control strategies, considering the nonlinearity and uncertainty of the system. Choi and Wereley [3] investigated the feasibility and effectiveness of electrorheological (ER) and MR fluid-based landing gear systems on attenuating dynamic load and vibration using sliding mode control. Wang and Carl [8] proposed the fuzzy logic control for the semiactive landing gear system; numerical results showed that the maximal structural load can be reduced with the semiactive landing gear. However, the control idea needs many sensors to sense the states of landing gear system, which will increase the cost and complexity of system.

Consequently, the main purpose of this study is to find a simple and effective control strategy to improve the ride comfort and stability of landing gear system; simultaneously, the control can potentially be employed in a practical case. In the prior work $[3,9]$, we have already investigated a landing gear system featuring MR fluids and demonstrated its feasibility and effectiveness on attenuating dynamics load and vibration due to the landing impact. As a continuation of the prior work, this study will propose a new control strategy, a human simulated intelligent control (HSIC), for the landing gear system. The control strategy has been successfully applied in the MR semiactive suspension system $[10,11]$. Many numerical and actual road tests show the effectiveness in reducing the vibration of vehicle suspension and improving the ride comfort.

To accomplish this goal, a two-DOF dynamic model of aircraft incorporated with an MRF-based landing gear is firstly constructed to simulate the course of touchdown. After analyzing the response of a classic touchdown, the HSIC is then proposed. Subsequently, the numerical simulation is performed to validate the effectiveness of the control strategy under different sink speeds and masses. In comparison, the skyhook control is also formulated. Finally, a great deal of numerical simulations considering variable masses and sink velocities are performed to evaluate the effectiveness of the proposed control algorithm.

\section{Modeling and Control Formulation of Landing Gear System Featured MR Absorber}

2.1. MR Absorber. In the work [3], the authors proposed one type of controllable MR absorber based on flow-mode, which is schematically shown in Figure 1. The absorber consists of working and gas compensation reservoirs. The working reservoir is separated into two chambers by the piston, in which an MR fluid is filled. There is an annual valve across

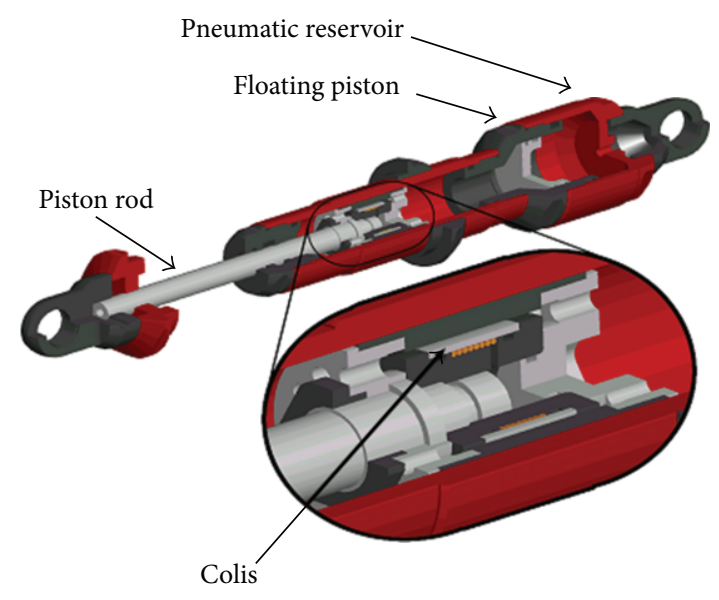

FIGURE 1: Schematic diagram of an MR absorber [3].

the piston with a winding magnetic coil. By the motion of the piston, the MR fluid will flow from one chamber to the other. In the absence of external magnetic field, the MR fluid can freely flow like linear viscous fluid, whereas the rheology of the MR fluid will undergo significantly controllable changes while applying a magnetic field. To compensate the bulk difference occupied by the piston rod during compression or rebound course, the pressured gas is filled in the gas compensation reservoirs.

Typically, the damping force of an MR absorber can be expressed as a combination of viscous damping force and coulomb damping force [10]:

$$
F=c_{s} v+F_{\mathrm{MR}} \operatorname{sign}(v),
$$

where $c_{s}$ denotes the damping constant due to viscous damping, $v$ is the relative velocity of MR absorber or piston rod relative to the absorber body, $F_{\mathrm{MR}}$ represents the controllable coulomb damping force which is a function of external magnetic field or electric current and sgn() indicates the sign function.

2.2. Two-DOF Landing Gear System with an MR Absorber. To formulate control strategy, a suitable dynamic model needs firstly to be constructed. In this study, one of two DOF dynamic models of a landing gear system is adopted in Figure 2 [9]. In this model, the landing object is treated as rigid body, which is slightly different to the actual case. The internal characteristics (stiffness and damping properties) are neglected in this study, although they are very important for the final landing scenario [7]. However, the simple model is sufficient to formulate the control strategy, and the model can describe main dynamic behaviors of a landing gear during touchdown.

In this figure, the sprung mass $m_{s}$ represents the mass of aircraft body and $m_{u}$ denotes the mass of tire. The MR absorber is employed between sprung mass and tire; it is also in parallel with a coil spring. 


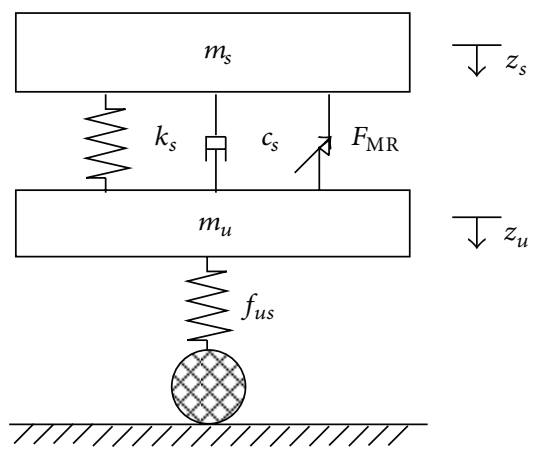

FIgURe 2: Dynamic modeling of an MR landing gear.

The motion equations of the landing gear system can be written as

$$
\begin{aligned}
& m_{s} \ddot{z}_{s}-m_{s} g+k_{s}\left(z_{s}-z_{u}\right)+c_{s}\left(\dot{z}_{s}-\dot{z}_{u}\right)+F_{\mathrm{MR}}+L_{f}=0, \\
& m_{u} \ddot{z}_{u}-m_{u} g-k_{s}\left(z_{s}-z_{u}\right)-c_{s}\left(\dot{z}_{s}-\dot{z}_{u}\right)-F_{\mathrm{MR}}+f_{u s}=0,
\end{aligned}
$$

where $g$ is the gravitation acceleration, $z_{s}, \dot{z}_{s}$, and $\ddot{z}_{s}$ represent the absolute displacement, velocity, and acceleration of sprung mass, respectively, $z_{u}$, $\dot{z}_{u}$, and $\ddot{z}_{u}$ represent the absolute displacement, velocity, and acceleration of unsprung mass, respectively, and $L_{f}$ is the lift force and

$$
L_{f}=\lg \left(m_{s}+m_{u}\right) \text {. }
$$

Here $l$ is the lift factor and is chosen to be 0.667 [7]. $f_{\text {us }}$ describes the nonlinear spring force of a tire given by $r z_{u}^{n}$. In this study, $r=480,000$ and $n=1.365$ [12]. $v_{0}$ represents the initial sink velocity.

If the state of the landing gear is set as $\mathbf{x}=\left[z_{s}, \dot{z}_{s}, z_{u}, \dot{z}_{u}\right]^{T}$ and control input is $u=\left[F_{\mathrm{MR}}\right]$, then (2) can be expressed as

$$
\dot{\mathbf{x}}=\mathbf{A x}+\mathbf{B} u+\mathbf{f}(\mathbf{x}),
$$

where

$$
\begin{gathered}
\mathbf{A}=\left[\begin{array}{cccc}
0 & 1 & 0 & 0 \\
-\frac{k_{s}}{m_{s}} & -\frac{c_{s}}{m_{s}} & \frac{k_{s}}{m_{s}} & \frac{c_{s}}{m_{s}} \\
0 & 0 & 0 & 1 \\
\frac{k_{s}}{m_{u}} & \frac{c_{s}}{m_{u}} & -\frac{k_{s}}{m_{u}} & -\frac{c_{s}}{m_{u}}
\end{array}\right], \quad \mathbf{B}=\left[\begin{array}{c}
0 \\
\frac{1}{m_{s}} \\
0 \\
-\frac{1}{m_{u}}
\end{array}\right] \\
\mathbf{f}(\mathbf{x})=\left[\begin{array}{c}
0 \\
g-\frac{L_{f}}{m_{s}} \\
0 \\
g+\frac{f_{u s}}{m_{u}}
\end{array}\right]
\end{gathered}
$$

\section{Formulation of Controller}

In (4), there are significant nonlinearity of MR absorber and uncertainties such as the mass of sprung mass and the initial

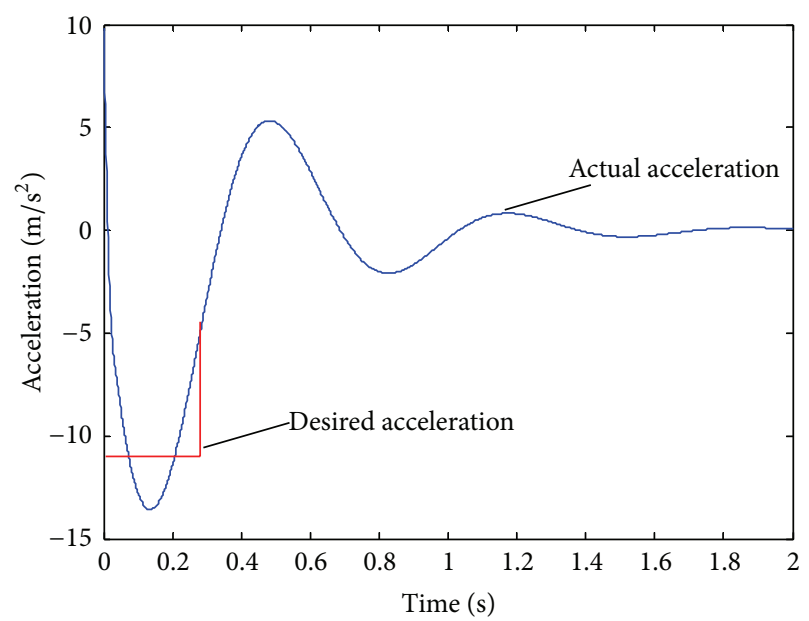

FIGURE 3: A classic acceleration time history of sprung mass.

sink velocity, which result in the difficulty of formulating a simple and effective control strategy. In our prior work [911], we investigated the HSIC in reducing the vibration of MR suspension system through simulation and road test. The results show that the control strategy is effective not only in steady dynamic course but also in transient dynamic course. Inspired by our prior work, the control idea is applied to the landing gear system in this study.

The HSIC algorithm, inspired by the excellent control experience of an expert, is proposed by Zhou and Bai early in 1983 [13]. With many years of development, the theory has been successfully in many perplexing processes and plants (such as delay system, multivariable system, and nonlinear system). The main and important characteristic of the theory consists of characteristic identification and multimode control, which simulate the human's intuition reasoning, namely, from identification to decision and from decision to operation $[11,14]$.

Generally speaking, the design procedure of applying the theory includes the analysis of controlled plant to obtain the desired phase portrait and the design of controller. In the following, the two steps will be discussed in order.

3.1. Determination of Desired Portrait of Motion. As a helicopter landing on ground, a classic acceleration time history of sprung mass is shown in Figure 3. There are two main control tasks for the landing gear system. One is to reduce the maximum deceleration or impact force. The other is to shorten the adjusting time. Obviously, the damping requirement is different for the different control tasks. A single control strategy is difficult to implement the two control tasks simultaneously. Therefore, it is necessary to apply different control model through simulating experts' control experience.

For the first control task, it is helpful to consider the man's reaction to a jump. To avoid the injure caused by the big impact from the land, a person has to bend his leg as soon as possible, which inspires us to make full use of stroke of MR absorber. Moreover, a human body is more sensitive to 


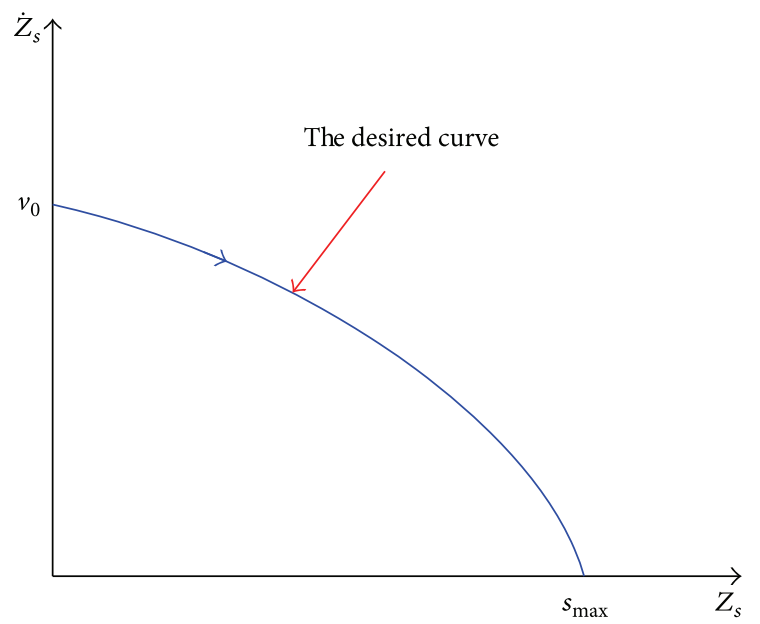

FIGURE 4: The desired phase portrait of displacement and velocity of sprung mass.

acceleration, which means that it is better for maintaining a constant deceleration.

For the initial sink velocity, $v_{0}$, we assume the deceleration to be kept constant desired $a_{d}$. The motion velocity is

$$
\dot{z}_{s}=v_{0}-a_{d} T
$$

where $T$ is the time when the MR absorber reaches the maximum stroke $s_{\max }$ and is given by

$$
T=\sqrt{\frac{2 s_{\max }}{a_{d}}}
$$

Substituting (7) into (6) and integrating gives

$$
z_{s}=\int_{0}^{T} \dot{z}_{s} d t=v_{0} T-\frac{1}{2} a_{d} T^{2}=-\frac{1}{2 a_{d}}\left(\dot{z}_{s}\right)^{2}+\frac{1}{2 a_{d}}\left(v_{0}\right)^{2} .
$$

From (8), the desired phase portrait of displacement and velocity of sprung mass in time domain is shown in Figure 4. The blue light is a quadratic function curve. Before reaching the maximum displacement of sprung mass, a constant deceleration needs to be maintained. To achieve the most desirable control performance, the maximum should always nearly be equal to the maximum stroke of the MR absorber.

The calculated or estimated desired deceleration is very important for improving control performance. Considering the nonlinearity and uncertainty of landing gear system, the method cannot be used anymore. In this study, we give an effective and simple method to estimate the infimum of desired acceleration if assuming that the desired deceleration can be guaranteed and the effective stroke equals the maximum stroke of the MR absorber. The desired deceleration can be calculated from (9) as

$$
a_{d}=\frac{v_{0}^{2}}{2 s_{\max }} .
$$

A genetic algorithm can be employed to optimize the deceleration as an alternative.
As mentioned earlier, the main control purpose is to maintain a constant deceleration during touchdown. Therefore, we can divide the course of touchdown into two phases in time domain. One is to reduce the maximum impact acceleration; the other is to avoid a big overshoot. It is obvious that different control modals are desirable for the two control phases. Considering the effectiveness and potential application, the acceleration feedback control is applied for reducing maximum impact acceleration whereas the skyhook control is adopted for reducing a big overshoot, because skyhook control is very effective in vibration attenuation in semiactive vibration control. Two control modes needs only to sense the acceleration and velocity signal, which is easily applied in practical case.

According to the above discussion, it is found that the acceleration feedback control and skyhook control may be effective in different phases. How to coordinate them and optimize control parameters will be discussed in the following.

3.2. Development of HSIC. Since the HSIC theory was proposed, the theory has advanced by Li and Wang [14] using schema theory. The term schema is originated from cognitive science, which refers to a mental structure we use to organize and simplify our knowledge of the world around us. The schema-based HSIC is a multilevel hierarchical structure information processing system. Each control mode is made up of several mode units and several control modes. Every control unit consists of direct control level, parameter correction level, and task adjustment level. The entire running control level forms a motor sensory intelligent schema (SMIS).

\subsubsection{Running Control Level}

\section{(1) Sensed Schema}

Definition 1 (sensed schema). It is an intelligent module which can be formulated by an agent's repeated learning and accumulating control experiences, and its structure is shown in Figure 5.

In this figure, the input information set $R$ includes the state signal from the plant itself or external environment. The state signal is the basis of selecting control action. In this study, $R=\left\{t, \dot{z}_{s}, \dot{z}_{u}\right\} \in \Sigma^{3}$ consists of the control time information and sink velocities of sprung mass and unsprung mass.

Similar to mankind's reaction to itself state or external environment, the input information will be sensed and sent to the block of characteristic identification. The function of the block of characteristic identification is to classify the sensed input information. The outputs of the block of characteristic identification are some characteristic elements, which will classify the state space into different control regions. The set of all characteristic elements are named as characteristic primitive set $Q$ :

$$
Q=\left\{q_{1}, q_{2}, q_{3}, q_{4}\right\}^{T}
$$




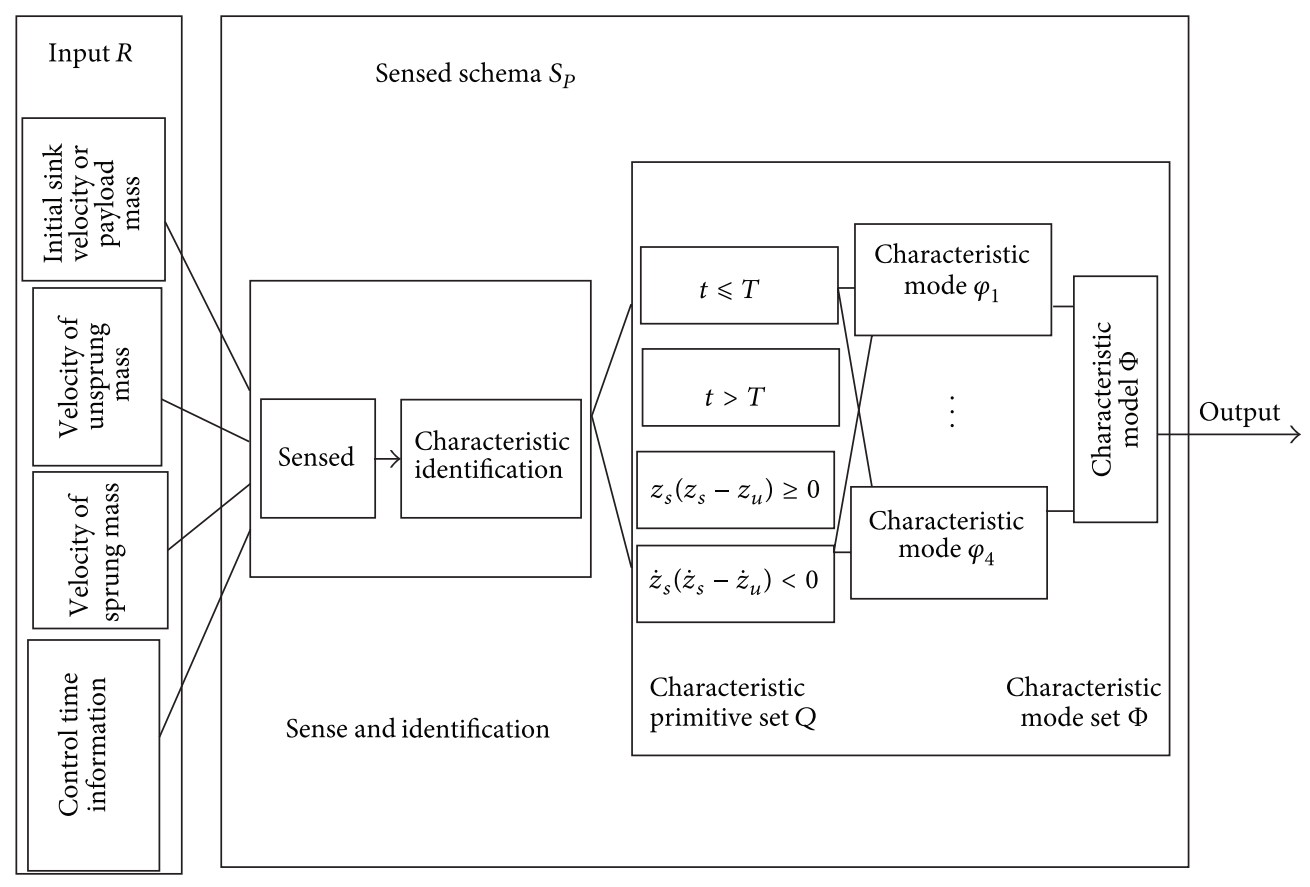

FIGURE 5: Structure of sensed schema.

in which $q_{1}=t$ if $t \leq T, q_{2}=t$ if $t>T, q_{3}=\dot{z}_{s}\left(\dot{z}_{s}-\dot{z}_{u}\right)$ if $\dot{z}_{s}\left(\dot{z}_{s}-\dot{z}_{u}\right) \geq 0$, and $q_{4}=\dot{z}_{s}\left(\dot{z}_{s}-\dot{z}_{u}\right)$ if $\dot{z}_{s}\left(\dot{z}_{s}-\dot{z}_{u}\right)<0$.

Combining the elements of the characteristic primitive set $Q$ through a logic operator $\otimes$, characteristic modes can be formulated. $\otimes$ is defined as $K \otimes Q=\cap_{i=1, j=1}^{4,4} q_{i} k_{i j} . k_{i j}$ is an element of $K$ and can be valued as $-1,0$, and 1, which means taking negative, zeros, and positive. Operational symbol is an "and" relation between two characteristic primitives. A characteristic mode is one kind of division of the system's dynamic information space $\Sigma$ according to the solution goal of the control problem and difference in control specifications, which is corresponding to the selection of the relation matrix. For example, the HSIC can recognize that the landing gear system is in the phase of crash and the control modal of acceleration will be automatically activated if $k_{1}=\{1,0,1,0\}$. In this study, $K=\left[\begin{array}{llll}1 & 0 & 1 & 0 \\ 1 & 0 & 0 & 1 \\ 0 & 1 & 1 & 0 \\ 0 & 1 & 0 & 1\end{array}\right]$. All characteristic modes will be combined into a characteristic mode set $\Phi$, which is also the output of the sensed schema.

The final output is the characteristic model set and can be gotten as

$$
\begin{aligned}
& \Phi=K \otimes Q=\left\{\varphi_{1} \mid t \leq T, \dot{z}_{s}\left(\dot{z}_{s}-\dot{z}_{u}\right) \geq 0,\right. \\
& \varphi_{2} \mid t \leq T, \dot{z}_{s}\left(\dot{z}_{s}-\dot{z}_{u}\right)<0 \text {, } \\
& \varphi_{3} \mid t>T, \dot{z}_{s}\left(\dot{z}_{s}-\dot{z}_{u}\right) \geq 0 \text {, } \\
& \left.\varphi_{4} \mid t>T, \dot{z}_{s}\left(\dot{z}_{s}-\dot{z}_{u}\right)<0\right\} .
\end{aligned}
$$

In summary, the mapping relation of the sensed schema between the input information space and the output characteristic mode set can be simply described by a fiveelement-group with order:

$$
S_{P}=\langle R, Q, K, \otimes, \Phi\rangle
$$

The output of the sensed schema will be the input of the following associated schema.

\section{(2) Motion Schema}

Definition 2 (motion schema). It is a stereotype embraced control strategy based on outside information of system and itself inner states, and its structure is shown in Figure 6.

The input information of the motion schema is the same as that of sensed schema. The physical sense of the motion schema is in the fact that it simulates how to adopt some actual control modes according to the sensing information like mankind. The function of the block of construct is to adaptively select the required feedback signal of the control mode.

The selection of control modes is dependent on the control tasks. Usually, there are some traditional control modes such as proportional control primitive $k_{p} e$, differential control primitive $k_{d} \dot{e}$, integral control primitive $k_{i} \int e d t$, and keeping control primitive $k_{h} \sum_{i=1}^{n} e_{m i}$. According to the above analysis, the acceleration feedback and skyhook control may be a better choice in this study. Therefore, the control mode primitive set $P$ can be written as $P=\left[p_{1}, p_{2}\right]^{T} \in \Sigma^{2}$, where $p_{1}$ denotes the acceleration feedback of $-k_{a}\left(a_{d}-\ddot{z}_{s}\right)$ and $p_{2}$ is the skyhook control mode of $k_{\text {sky }} \dot{z}_{s}$. 


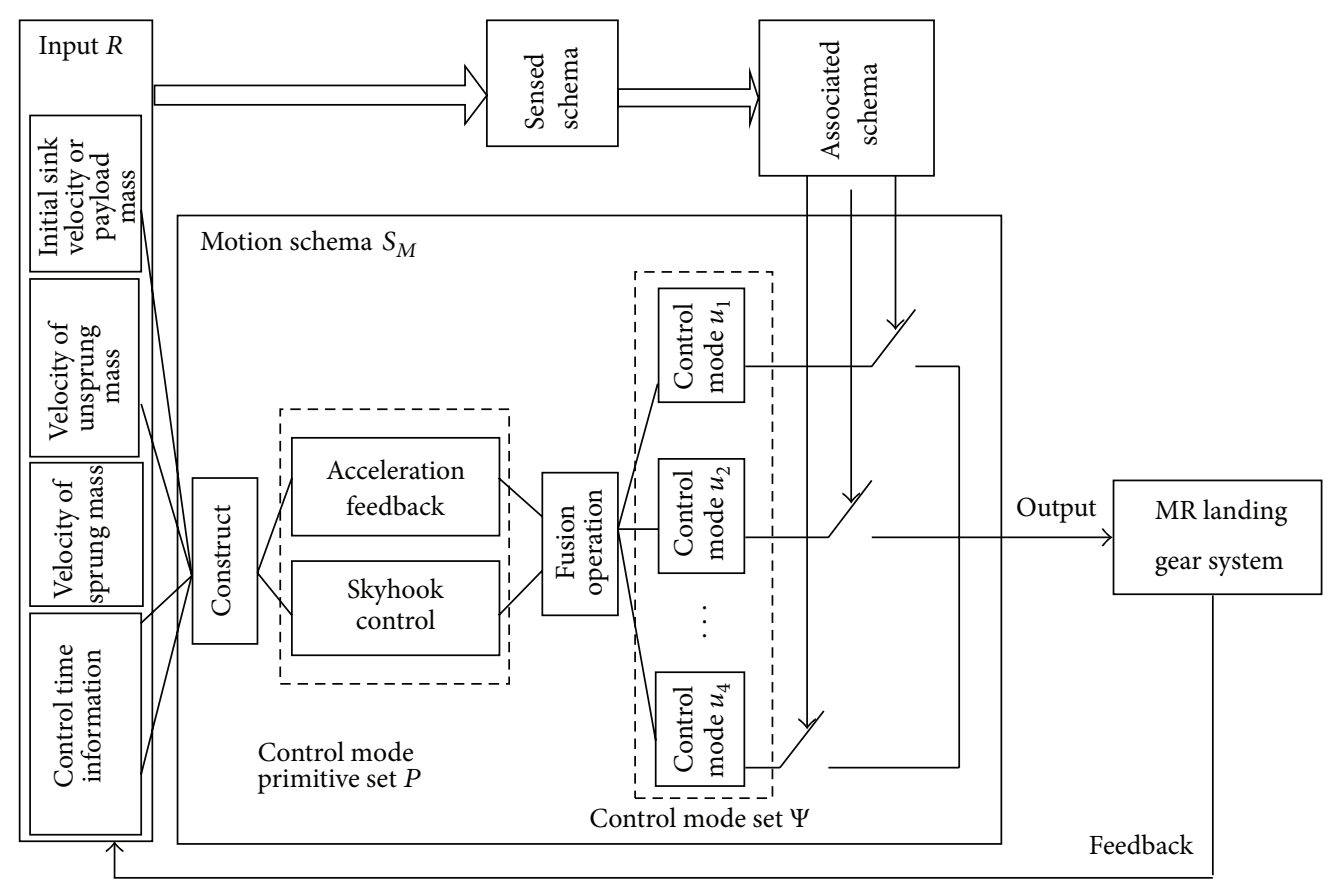

FIGURE 6: Structure of motion schema.

The block of fusion operation is to logically combine the control modes. There is an operation relation between the control mode primitive set and the control mode set:

$$
\Psi=\left[\begin{array}{l}
u_{1} \\
u_{2} \\
u_{3} \\
u_{4}
\end{array}\right]=L P=\left[\begin{array}{c}
2 \\
\sum_{j=1} l_{1 j} p_{j} \\
\sum_{j=1}^{2} l_{2 j} p_{j} \\
\sum_{j=1}^{2} l_{3 j} p_{j} \\
\sum_{j=1}^{2} l_{4 j} p_{j}
\end{array}\right]=\left[\begin{array}{c}
-k_{a}\left(a_{d}-\ddot{z}_{s}\right) \\
0 \\
k_{\text {sky }} \dot{z}_{s} \\
0
\end{array}\right]
$$

in which $l_{i j}$ is an element of $L$ and can be valued as -1 , 0 , and 1 , which denote taking negative, zero, and positive, respectively. In this study, $L=\left[\begin{array}{ll}1 & 0 \\ 0 & 0 \\ 0 & 1 \\ 0 & 0\end{array}\right]$. The zero output is due to the semiactive features of the MR damper. The control mode set is connected to the MR landing gear system through a group of logic switch. The logic rules will be generated by the associated schema.

For brevity, the motion schema can be formulated as a five-element group with order:

$$
S_{M}=\langle R, P, L, \Psi, U\rangle .
$$

\section{(3) Associated Schema}

Definition 3 (associated schema). It is used to coordinate the relation between sensed schema and motion schema, which simulates human being's intuition reasoning and decision process. The structure is shown in Figure 7.

In this figure, once the sensed schema and motion schema are obtained through the block of computation, the function mapping relation among the characteristic mode set and control mode set is determined by the block of intuition reasoning and decision making. The physical sense is that one mankind has a double mapping when doing something. He firstly needs to judge qualitatively the object and then adopts quantitatively control behavior. The output of the block of intuition reasoning and decision making is some logic values, which will activate the corresponding the control mode if the logic switch is true.

Generally, the function of the association schema is to obtain production rules "IF...Then...". The process can be expressed as

$$
\Omega: \Phi \longrightarrow \Psi
$$

where $\Omega=\left\{\omega_{1}, \omega_{2}, \omega_{3}, \omega_{4}\right\}, \omega_{i}=\left\{\right.$ if $\varphi_{i}$ then $\left.\psi_{i}\right\} \in \Sigma^{4}$ (qualitative mapping), and $\Psi: R \rightarrow U, \Psi=\left[\begin{array}{llll}\psi_{1} & \psi_{2} & \psi_{3} & \psi_{4}\end{array}\right]^{T}$ (quantitative mapping).

3.2.2. Parameter Adjustment Level. It is obvious that the HSIC with the fixed control parameter cannot be able adaptively to meet the requirement of all impact scenarios of landing gear system. Therefore, the control parameter $k_{a}$ in (13) is dependent on the sink velocity and mass of sprung mass. The relation will be determined by genetic algorithm in Section 4 .

3.2.3. Control Structure of HSIC. After designing the sensed schema, motion schema and associated schema, the entire control structure of HSIC can be combined as a three-element group with order (which is shown in Figure 8)

$$
S_{\mathrm{KG}}=\left\langle S_{p}, S_{M}, S_{A}\right\rangle \text {. }
$$




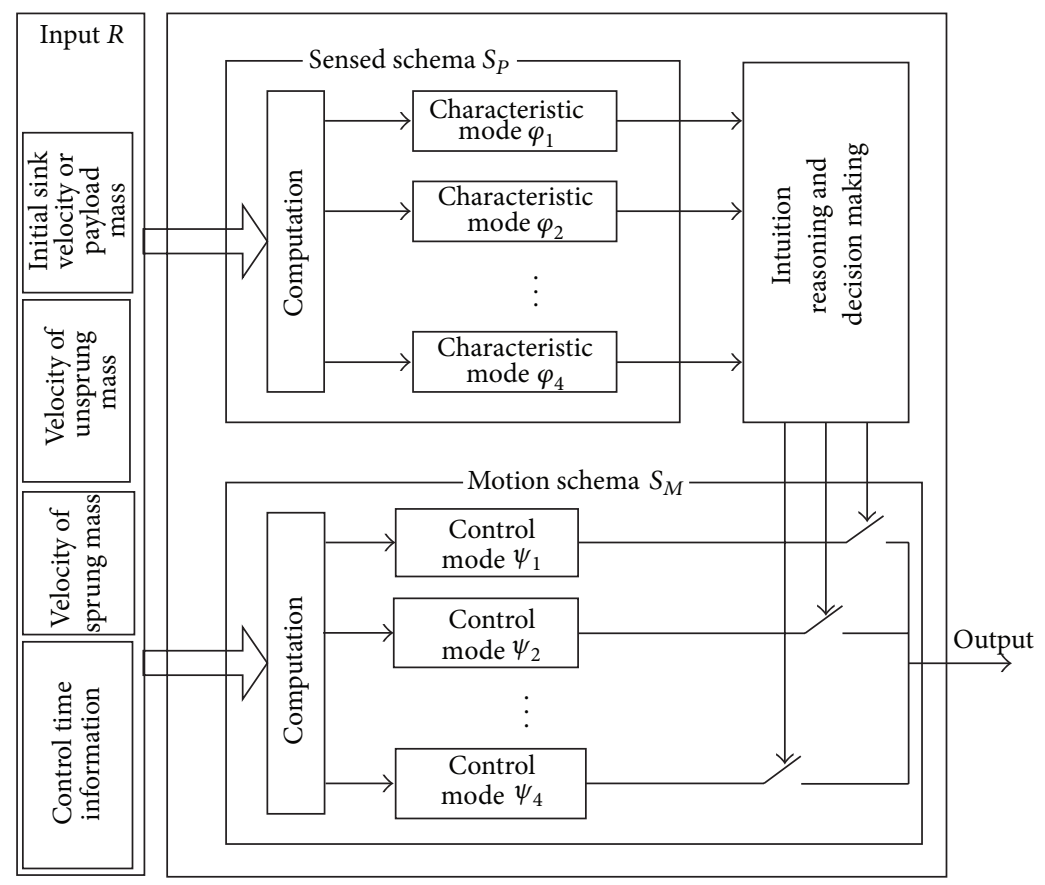

FIGURE 7: Structure of associated schema.

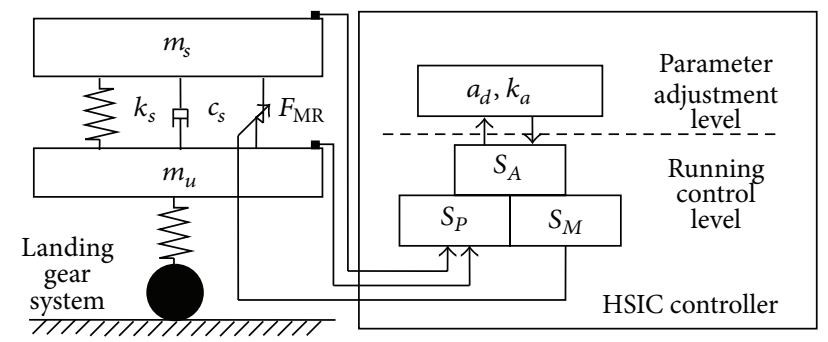

FIgURE 8: The HSIC controller structure-based SMIS for MR landing gear system.

According to above discussion, the final control law can be simply written as in Algorithm 1.

\section{Control Parameter Optimization}

Control parameters of the HSIC that need to be determined initially include $a_{d}$ and $k_{a}$ according to the impact scenario of landing gear system. Usually, the course of determination for those threshold value parameters needs much trial or error. Therefore, in this paper, a genetic algorithm is proposed to tune the parameters through the Matlab 7.0/Simulink. In Section 3.1, the issue of desired deceleration is discussed and the value can be calculated simply from (9). To estimate the accurate value of desired deceleration, the genetic algorithm is also used to search the optimal deceleration. In summary, there are three control parameters, $k_{a}, k_{\text {sky }}$, and $a_{d}$ of HSIC that needed to be optimized. Figure 9 gives the optimal procedure of control parameters. The objective of optimization is to achieve the minimal deceleration of sprung mass. As a result,

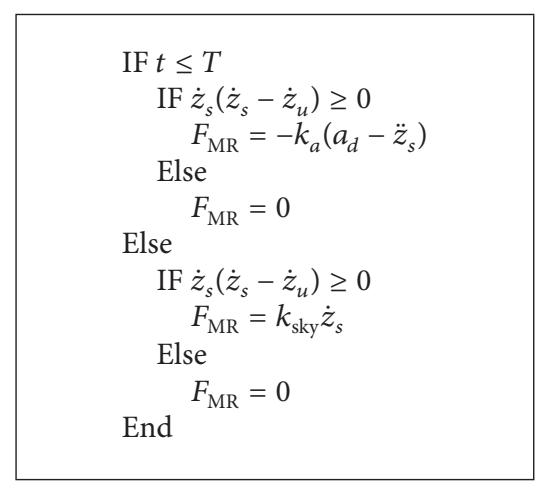

Algorithm 1

the fitness of genetic algorithm is evaluated by the maximum deceleration during each simulation of dynamic model. The numerical time is set to 2 seconds for each simulation.

The real number encoding is adopted in this paper. The length of chromosome is determined by the number of the control parameters. If $\left(r_{1}, r_{2}, r_{3}\right)$ is the optimal solution, the initial chromosomes can be obtained by

$$
r_{i}=l_{i}+\beta\left(u_{i}-l_{i}\right),
$$

where $l_{i}$ and $u_{i}$ are the lower limit and the upper limit of optimized parameters, respectively. $\beta$ is the proportional factor.

To improve control performance, the fitness function is chosen as the maximum impact deceleration. The crossover operators used here are one-cut-point crossover by convex crossover. The mutation operator used in this paper is convex combination. The parameters used in the simulation of 


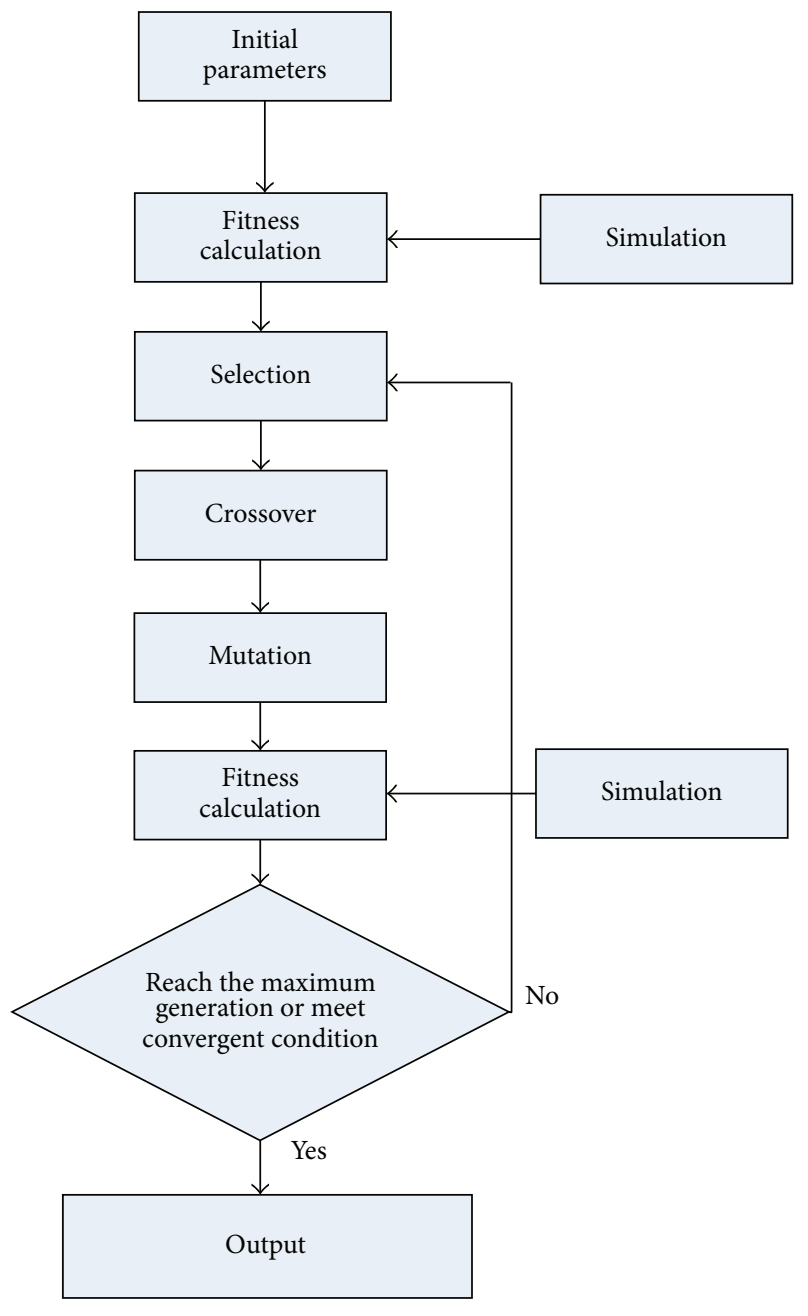

FIGURE 9: The optimal procedure of control parameters.

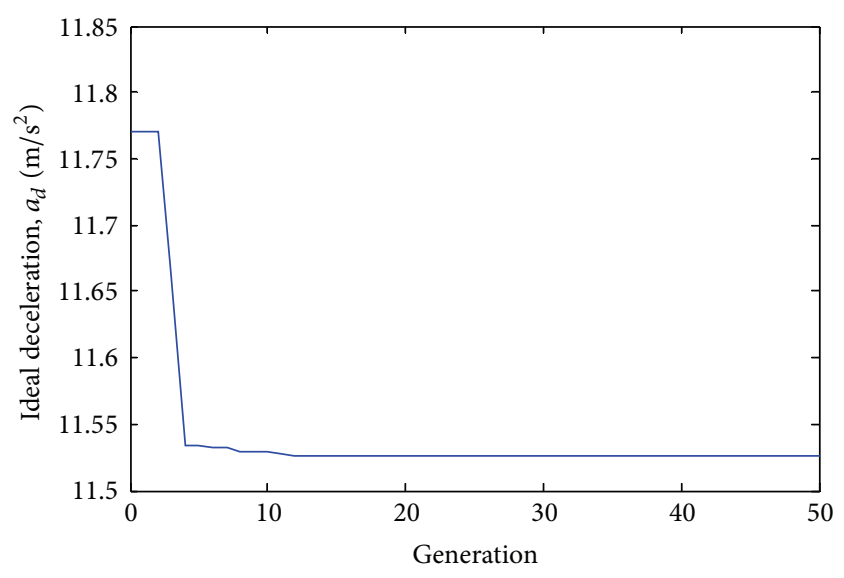

FIGURE 10: The convergent procedure of fitness value with generations.

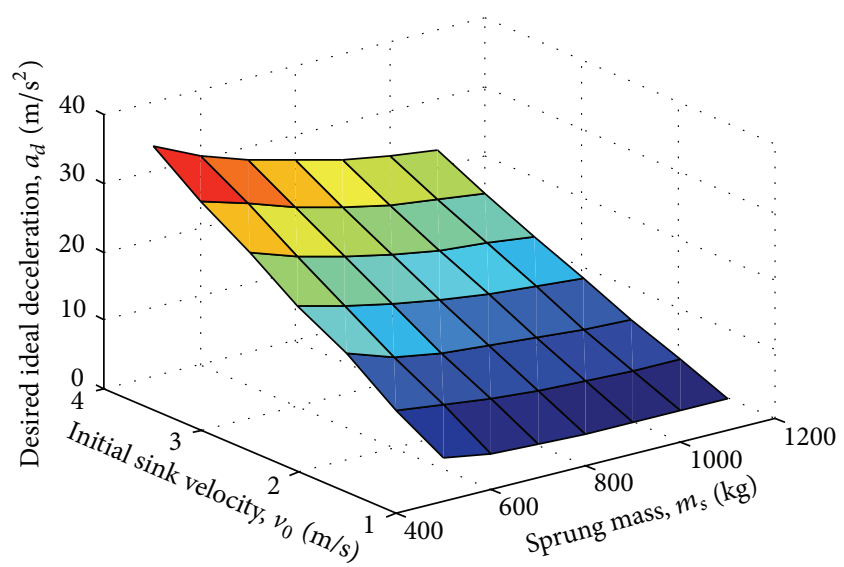

FIGURE 11: The relation of desired deceleration with sink velocity and sprung mass.

the genetic algorithm are population size $=50$, mutation probability $=0.3$, and crossover probability $=0.1$. As an illustration, Figure 10 shows the convergent course of the desired deceleration for the sink velocity of $2 \mathrm{~m} / \mathrm{s}$ and sprung mass of $800 \mathrm{~kg}$. It can be found that the convergent is very fast.

To determine the specific function relations between desired deceleration or acceleration feedback gain and sink velocity as well as sprung mass, many simulations are performed considering all kinds of combinatorial sink velocity as well as sprung mass. The results are shown in Figures 11 and 12. From Figure 11, it can be found that the desired deceleration will grow with the increment of sink velocity and decrease slightly with the increment of sprung mass. Figure 12 gives the relation of desired acceleration feedback gain with sink velocity and sprung mass. It can be seen that the sprung mass has bigger effect on the acceleration feedback gain than the sink velocity.

To reduce the complexity of computation, the linear surface fitting method is adopted in this study. The simple

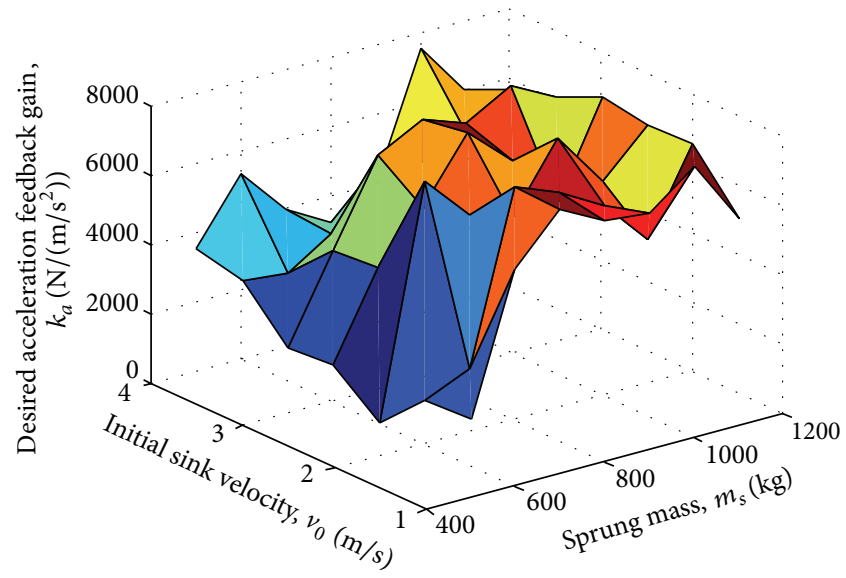

FIGURE 12: The relation of desired deceleration with sink velocity and sprung mass. 
specific function relations can be evaluated and expressed as follows:

$$
\begin{gathered}
a_{d}=7.79 v_{0}-0.0086 m_{s}+3.1536, \\
k_{a}=5.74 v_{0}+6.23 m_{s}+592.44 .
\end{gathered}
$$

The method of online identifications of $v_{0}$ and $m_{s}$ is studied by some researchers [15]. Once the values of $v_{0}$ and $m_{s}$ are determined, the feedback gain can be easily calculated. Figures 13 and 14 give the results after surface fitting. According to these figures or (18)-(19), the control parameters can be adjusted adaptively with the change of impact scenarios.

\section{Numerical Simulation and Discussion}

To evaluate the control performance and adaptive ability of MR landing gear system, we constructed the numerical model based on Matlab/Simulink. The system and control parameters employed in this study are given in Table 1.

In order to figure out the sensitivity of the desired deceleration value on the control performance, thirteen different deceleration values are applied in the control numerical experiment. The results are shown in Figure 15. Among all those deceleration values, point A represents the evaluated deceleration value according to (18). It can be found that all situations can achieve good control performance. It is noted that the best control performance is obtained not at point $\mathrm{A}$ but at the point B due to the linear surface fitting error of (18). Nevertheless, the results indicate that the HSIC has strong robust considering the difficulty in determining the value of desired deceleration in real environment.

To simulate the different scenarios of touchdown, the mass of sprung mass can be increased or reduced, so does the sink velocity of landing gear system. For comparison purpose, the skyhook control law is also adopted, and its control gain is also optimized by the genetic algorithm. Consider

$$
u= \begin{cases}k_{\text {sky }} \dot{z}_{s}, & \text { if } \dot{z}_{s}\left(\dot{z}_{s}-\dot{z}_{u}\right)>0, \\ 0, & \text { if } \dot{z}_{s}\left(\dot{z}_{s}-\dot{z}_{u}\right) \leq 0\end{cases}
$$

Once the set value of desired deceleration equals or falls into a small region nearby the optimal deceleration, the control performance of HSIC will be significantly improved compared to that of acceleration feedback control, skyhook control or passive, which is shown in Figure 16. From this figure, it can be seen that the maximum impact acceleration almost maintains the value of the desired deceleration. The reduction of maximum acceleration of HSIC is over $11 \%$ compared to that of passive case. The maximum impact force can also be greatly reduced, which means that the discomfort caused by the strong impact will be significantly alleviated during touchdown. In addition, the control strategy needs almost the same effective stroke of the skyhook control. Although the required stroke of the skyhook control is smaller than that of the passive, the impact acceleration is even bigger than that of the passive. This implies that the skyhook controller is good at reducing the damper stroke but is not good at reducing the acceleration reduction for the

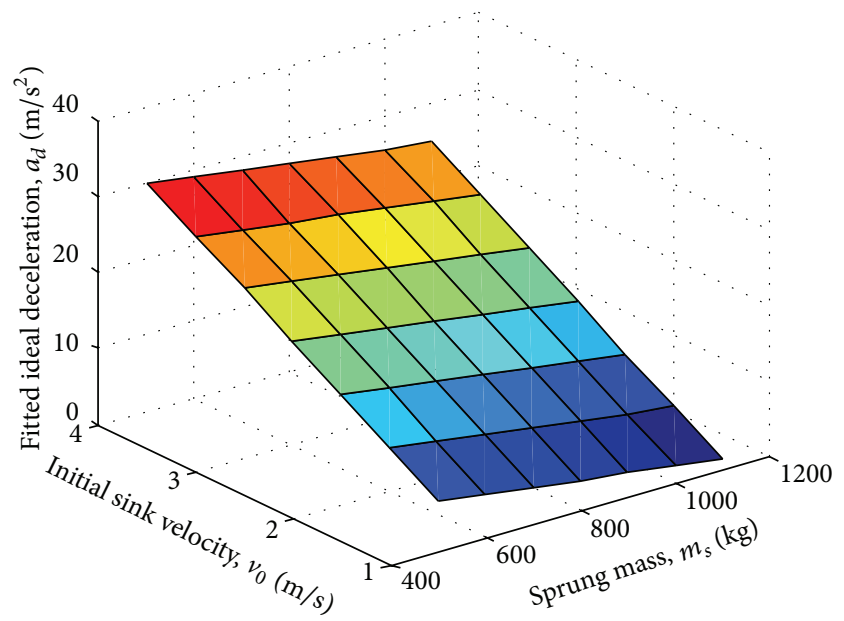

FIGURE 13: The relation of fitted ideal deceleration with sink velocity and sprung mass after surface fitting.

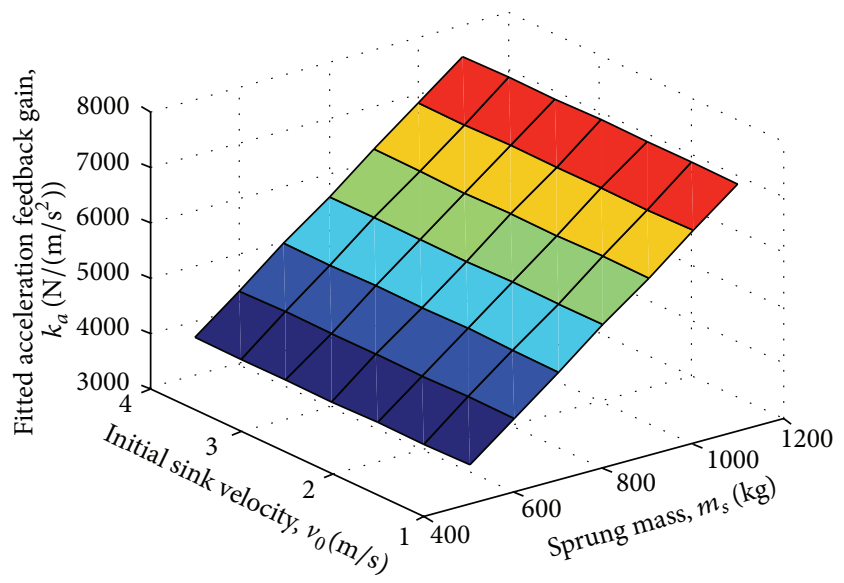

FIGURE 14: The relation of fitted acceleration feedback gain with sink velocity and sprung mass after surface fitting.

TABLE 1: System and control parameters.

\begin{tabular}{lccc}
\hline Quantity & Symbol & Value & Units \\
\hline Mass of sprung mass & $m_{s}$ & 800 & $\mathrm{~kg}$ \\
Mass of unsprung mass & $m_{u}$ & 15.3 & $\mathrm{~kg}$ \\
$\begin{array}{l}\text { Spring stiffness of coil } \\
\text { Damping constant of MR }\end{array}$ & $k_{s}$ & 80,000 & $\mathrm{~N} / \mathrm{m}$ \\
$\begin{array}{l}\text { absorber } \\
\begin{array}{l}\text { Maximum controllable } \\
\text { damping force of absorber }\end{array}\end{array}$ & $c_{s}$ & 4,500 & $\mathrm{Ns} / \mathrm{m}$ \\
\hline
\end{tabular}

touchdown of the landing gear system. From this figure, it can be found that although the acceleration feedback control can reduce the maximum impact acceleration, a big oscillation appears after the initial touchdown. Therefore, the control strategy is not suitable for the whole touchdown course and is not compared to the HSIC and the skyhook control anymore. At last, it is noted that the HSIC can also achieve the improvement of vibration of unsprung mass. 
TABle 2: Maximum acceleration reduction compared to passive case.

\begin{tabular}{|c|c|c|c|c|c|}
\hline \multirow{2}{*}{ Sprung mass } & \multirow{2}{*}{ Strategy } & \multicolumn{4}{|c|}{ Sink rate } \\
\hline & & $1 \mathrm{~m} / \mathrm{s}$ & $2 \mathrm{~m} / \mathrm{s}$ & $3 \mathrm{~m} / \mathrm{s}$ & $4 \mathrm{~m} / \mathrm{s}$ \\
\hline \multirow{2}{*}{$500 \mathrm{~kg}$} & Skyhook & $5.66 \%$ & $-2.91 \%$ & $-6.19 \%$ & $-7.71 \%$ \\
\hline & HSIC & $27.15 \%$ & $11.19 \%$ & $7.07 \%$ & $5.03 \%$ \\
\hline \multirow{2}{*}{$700 \mathrm{~kg}$} & Skyhook & $9.04 \%$ & $2.85 \%$ & $-0.05 \%$ & $-1.54 \%$ \\
\hline & HSIC & $38.79 \%$ & $17.88 \%$ & $11.53 \%$ & $8.21 \%$ \\
\hline \multirow{2}{*}{$800 \mathrm{~kg}$} & Skyhook & $8.08 \%$ & $8.08 \%$ & $7.89 \%$ & $7.74 \%$ \\
\hline & HSIC & $17.97 \%$ & $11.86 \%$ & $9.32 \%$ & $7.44 \%$ \\
\hline \multirow{2}{*}{$900 \mathrm{~kg}$} & Skyhook & $9.97 \%$ & $5.20 \%$ & $2.63 \%$ & $1.24 \%$ \\
\hline & HSIC & $41.59 \%$ & $20.94 \%$ & $12.93 \%$ & $9.27 \%$ \\
\hline \multirow{2}{*}{$1100 \mathrm{~kg}$} & Skyhook & $10.18 \%$ & $6.34 \%$ & $4.03 \%$ & $2.73 \%$ \\
\hline & HSIC & $41.43 \%$ & $21.91 \%$ & $13.61 \%$ & $9.87 \%$ \\
\hline
\end{tabular}

TABLE 3: Maximum stroke reduction compared to passive case.

\begin{tabular}{|c|c|c|c|c|c|}
\hline \multirow{2}{*}{ Sprung mass } & \multirow{2}{*}{ Strategy } & \multicolumn{4}{|c|}{ Sink rate } \\
\hline & & $1 \mathrm{~m} / \mathrm{s}$ & $2 \mathrm{~m} / \mathrm{s}$ & $3 \mathrm{~m} / \mathrm{s}$ & $4 \mathrm{~m} / \mathrm{s}$ \\
\hline \multirow{2}{*}{$500 \mathrm{~kg}$} & Skyhook & $9.54 \%$ & $9.26 \%$ & $8.95 \%$ & $8.75 \%$ \\
\hline & HSIC & $13.29 \%$ & $7.89 \%$ & $6.29 \%$ & $5.38 \%$ \\
\hline \multirow{2}{*}{$700 \mathrm{~kg}$} & Skyhook & $8.49 \%$ & $8.43 \%$ & $8.20 \%$ & $8.04 \%$ \\
\hline & HSIC & $17.72 \%$ & $11.13 \%$ & $8.97 \%$ & $7.28 \%$ \\
\hline \multirow{2}{*}{$800 \mathrm{~kg}$} & Skyhook & $9.65 \%$ & $4.25 \%$ & $1.53 \%$ & $0.09 \%$ \\
\hline & HSIC & $41.10 \%$ & $19.76 \%$ & $12.42 \%$ & $8.90 \%$ \\
\hline \multirow{2}{*}{$900 \mathrm{~kg}$} & Skyhook & $7.73 \%$ & $7.78 \%$ & $7.62 \%$ & $7.48 \%$ \\
\hline & HSIC & $18.88 \%$ & $12.30 \%$ & $9.22 \%$ & $7.47 \%$ \\
\hline \multirow{2}{*}{$1100 \mathrm{~kg}$} & Skyhook & $7.15 \%$ & $7.27 \%$ & $7.15 \%$ & $7.03 \%$ \\
\hline & HSIC & $17.71 \%$ & $12.42 \%$ & $9.27 \%$ & $7.62 \%$ \\
\hline
\end{tabular}

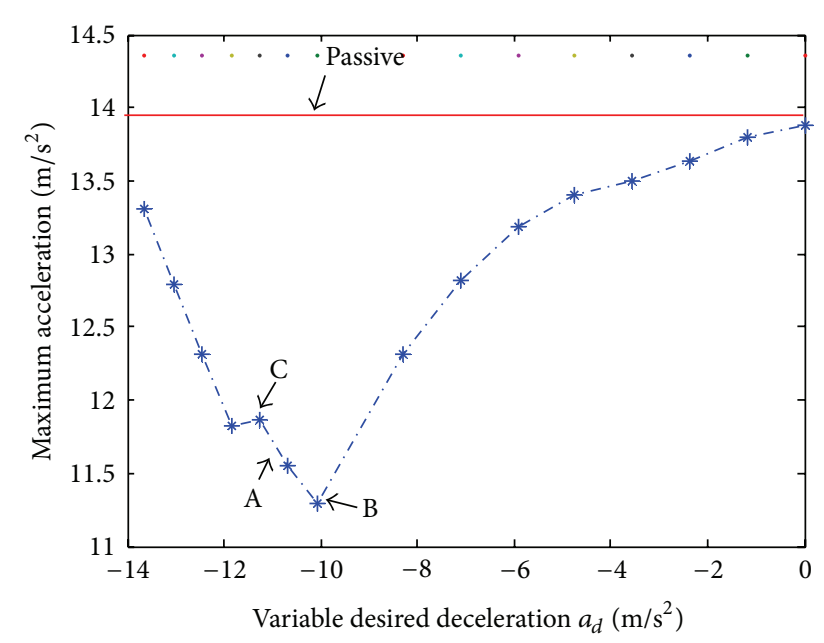

FIGURE 15: Sensitive analysis of desired deceleration on the control performance.

There are two gains of skyhook applied in this study. One is the $1200 \mathrm{Ns} / \mathrm{m}$ which is chosen to make both skyhook control and HISC keep almost the same stroke value so that they can compare to each other in terms of the improvement of impact acceleration. The corresponding results are shown in Figure 16. The other is $2500 \mathrm{Ns} / \mathrm{m}$, which is chosen in order to achieve the best improvement of impact deceleration. Correspondingly, the results are given in Figure 17 and Tables 1 and 2. In addition, the feedback control strategy during the whole crash course is also adopted in comparison.

The comparison results of different sink velocities and masses are demonstrated in Figure 16 and Tables 2 and 3. The results show that the maximum deceleration will grow with the increment of sink velocities or decrement of masses. The HSIC exhibits the better adaptive ability. In some cases, the skyhook control cannot achieve the reduction of impact. It is noted that the HSIC and skyhook control can achieve the best control performance when the mass of sprung mass changes to $1100 \mathrm{~kg}$ for different sink velocities. At this situation, the control performance of HSIC is also prior to that of skyhook control.

\section{Conclusion}

In this study, the semiactive control of a landing gear system featured with a MR absorber during touchdown has been investigated. An intelligent control strategy, human simulated intelligent control (HSIC), is proposed. The genetic algorithm is employed to optimize the control parameters of HSIC. Numerical simulations considering the variety of sink velocities and masses have been performed to check 


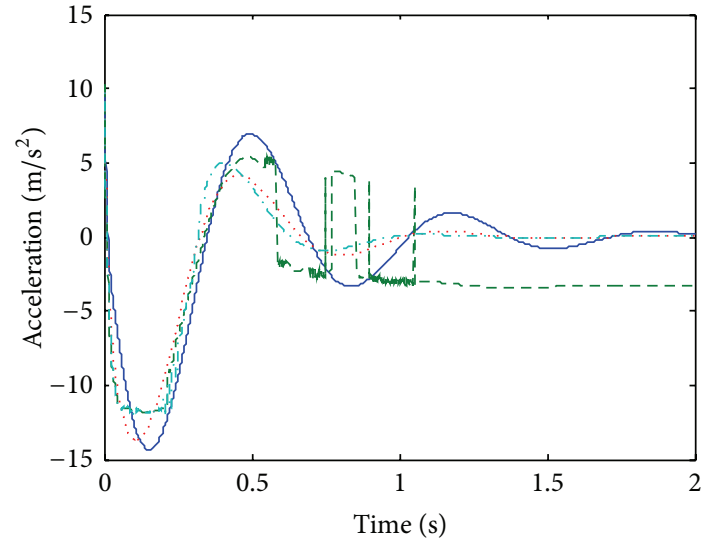

— Off-control ….. Skyhook control - - - Acceleration feedback .... HSIC

(a) Vibration acceleration of sprung mass $\left(v_{0}=2 \mathrm{~m} / \mathrm{s}\right)$

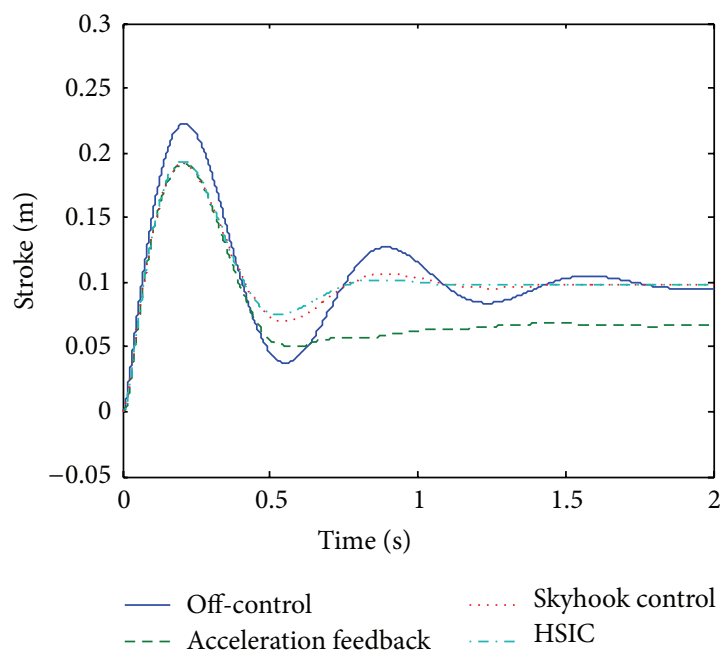

(c) Displacement of MR absorber $\left(v_{0}=2 \mathrm{~m} / \mathrm{s}\right)$

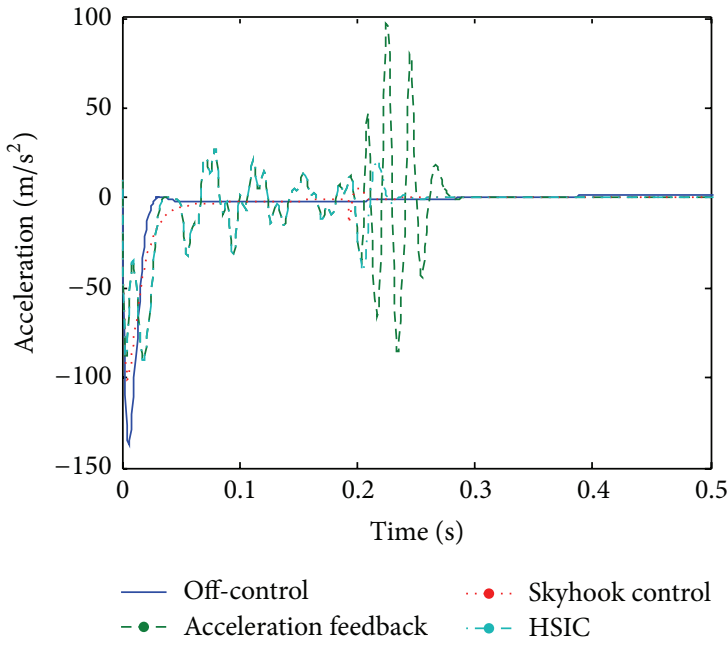

(b) Vibration acceleration of unsprung mass $\left(v_{0}=2 \mathrm{~m} / \mathrm{s}\right)$

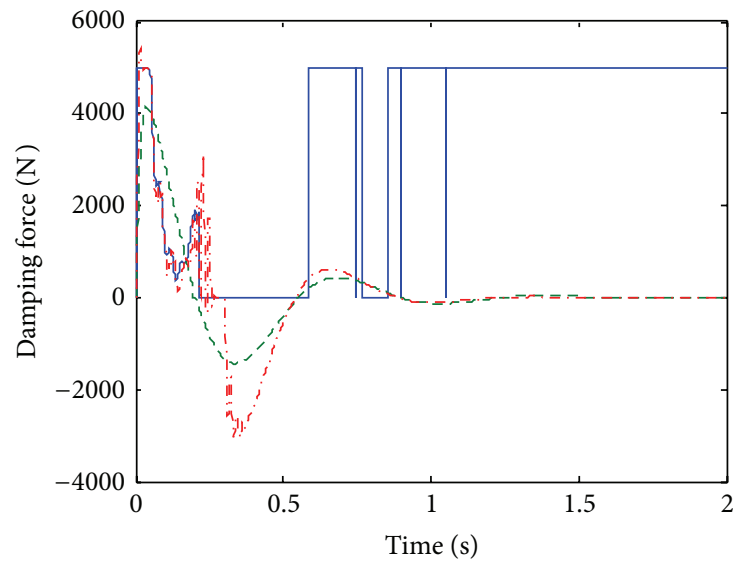

- Acceleration feedback _..- HSIC - - - Skyhook control

(d) Controllable damping force

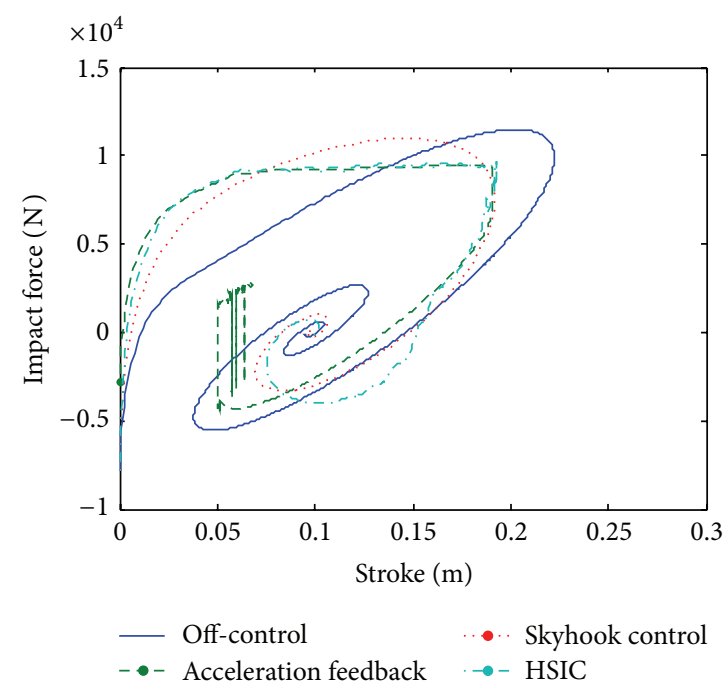

(e) Relation of impact force and stroke

FIGURE 16: The control performance comparison with sink velocity of $2 \mathrm{~m} / \mathrm{s}$ and mass of sprung mass of $800 \mathrm{~kg}$. 


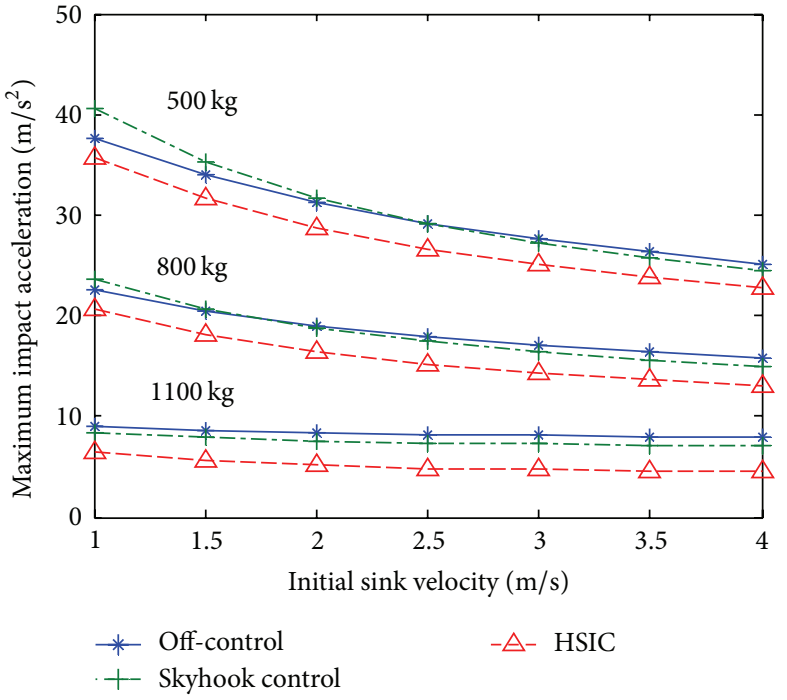

(a) Maximum impact acceleration

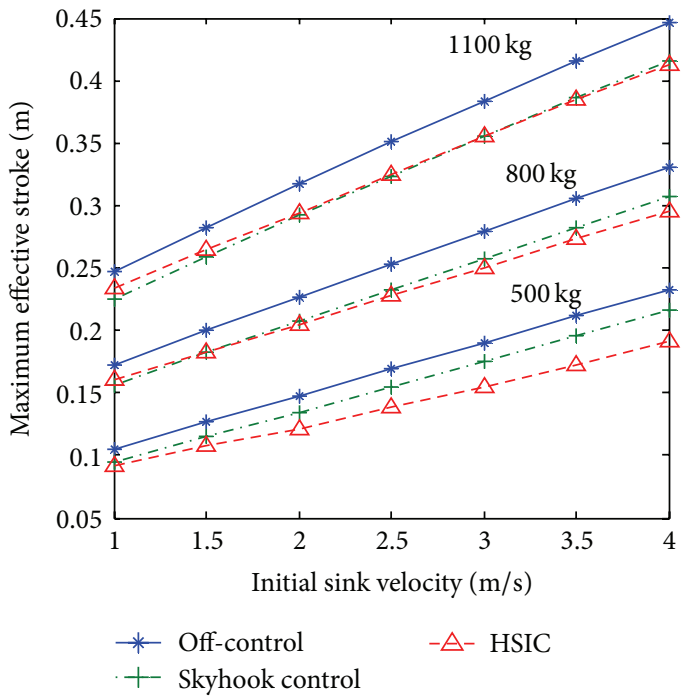

(b) Maximum stroke of MR absorber

FIGURE 17: The control performance comparison with different sink velocities and masses.

the effectiveness and adaptive ability of the proposed control algorithm. It can be concluded from the numerical results that

(1) compared to passive or based skyhook control system landing gear system, the control strategy can effectively reduce the maximum impact acceleration and maintain the minimum change of acceleration during touchdown, simultaneously mains minimum stroke;

(2) the control strategy performs very well and exhibits strong robustness in different situations such as variable sink velocities and sprung masses;

(3) the control strategy can easily be applied in practical landing gear system.

In the future, the more precise model of MR absorber will be incorporated, and then experimental research will also be performed to check the actual control performance.

\section{Acknowledgments}

This research is supported financially by the National Natural Science Foundation of China (Project nos. 51275539 and 60804018), the Fundamental Research Funds for the Central Universities (CDJZR12110058 and CDJZR13135553), and the Program for New Century Excellent Talents in University (NCET-13-0630). Dr. Y. T. Choi and Professor N. M. Wereley in University of Maryland provided the data of the MR shock absorber and gave some helpful suggestions in improving the paper. These supports are gratefully acknowledged.

\section{References}

[1] D. C. Batterbee, N. D. Sims, R. Stanway, and Z. Wolejsza, "Magnetorheological landing gear: 1. A design methodology,"
Smart Materials and Structures, vol. 16, no. 6, pp. 2429-2440, 2007.

[2] D. C. Batterbee, N. D. Sims, R. Stanway, and M. Rennison, "Magnetorheological landing gear: 2. Validation using experimental data," Smart Materials and Structures, vol. 16, no. 6, pp. 24412452, 2007.

[3] Y.-T. Choi and N. M. Wereley, "Vibration control of a landing gear system featuring electrorheological/magnetorheological fluids," Journal of Aircraft, vol. 40, no. 3, pp. 432-439, 2003.

[4] G. Mikułowski and Ł. Jankowski, "Adaptive landing gear: optimum control strategy and potential for improvement," Shock and Vibration, vol. 16, no. 2, pp. 175-194, 2009.

[5] G. L. Ghiringhelli, "Evaluation of a landing gear semi- active control system for complete aircraft landing," Aerotecnica Missili e Spazio, vol. 83, no. 6, pp. 21-31, 2004.

[6] G. L. Ghiringhelli, "Testing of semiactive landing gear control for a general aviation aircraft," Journal of Aircraft, vol. 37, no. 4, pp. 606-616, 2000.

[7] G. M. Mikułowski and J. Holnicki-Szulc, "Adaptive landing gear concept-feedback control validation," Smart Materials and Structures, vol. 16, no. 6, pp. 2146-2158, 2007.

[8] X. M. Wang and U. Carl, "Fuzzy control of aircraft semiactive landing gear system," in Proceedings of the 37th Aerospace Sciences Meeting and Exhibit, pp. 1-11, 1999.

[9] X. Dong, M. Yu, C. Liao, and W. Chen, "Adaptive semiactive bumper for aircraft," Journal of Southwest Jiaotong University, vol. 44, no. 5, pp. 748-752, 2009.

[10] X. M. Dong, M. Yui, Z. Li, C. Liao, and W. Chen, "A comparison of suitable control methods for full vehicle with four MR dampers, part I: formulation of control schemes and numerical simulation," Journal of Intelligent Material Systems and Structures, vol. 20, no. 7, pp. 771-786, 2009.

[11] X.-M. Dong, Z.-S. Li, M. Yu, C.-R. Liao, and W.-M. Chen, "Human simulated intelligent control and its application in magneto-rheological suspension," Control Theory and Applications, vol. 27, no. 2, pp. 245-253, 2010. 
[12] P. J. Reddy, V. T. Nagaraj, and V. Ramamurti, "Analysis of a semi-active levered suspension landing gear system with some parametric study," Journal of Dynamic Systems, Measurement and Control, Transactions of the ASME, vol. 218, no. 3, pp. 218224, 1984.

[13] Q. Zhou and J. Bai, "An intelligent controller of novel design," in Proceedings of The Multi-National Instrument Conference, Part 1, pp. 137-149, Shanghai, China, 1983.

[14] Z. Li and G. Wang, "Schema theory and human simulated intelligent control," in Proceedings of the IEEE on Robotics \& Intelligent Systems and Signal Processing, pp. 524-530, Changsha, China, 2003.

[15] K. Sekula, Cz. Graczykowski, and J. Holnicki-Szulc, "On-line impact load identification," Shock and Vibration, vol. 20, pp. 123-141, 2013. 


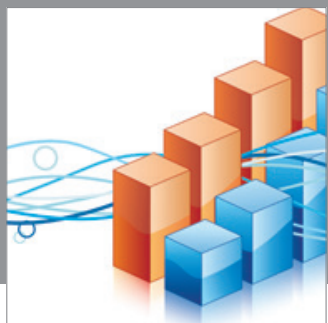

Advances in

Operations Research

mansans

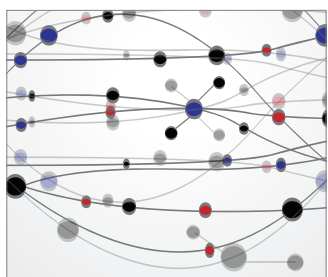

The Scientific World Journal
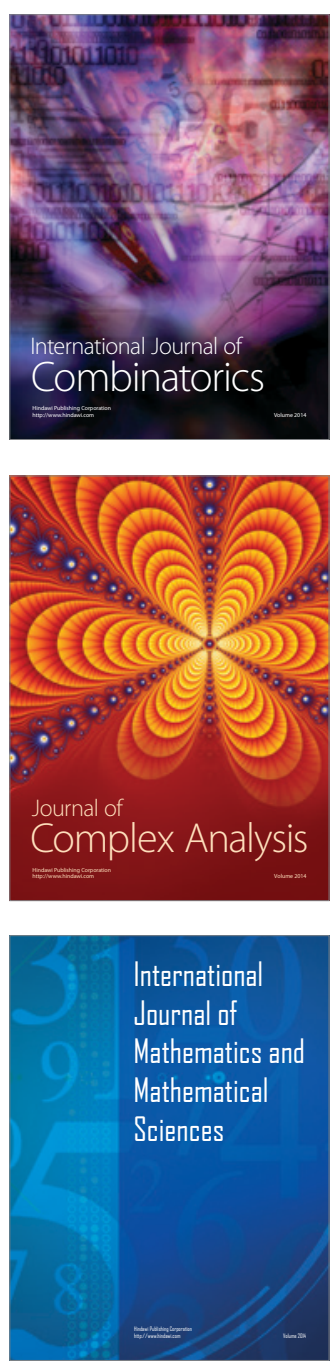
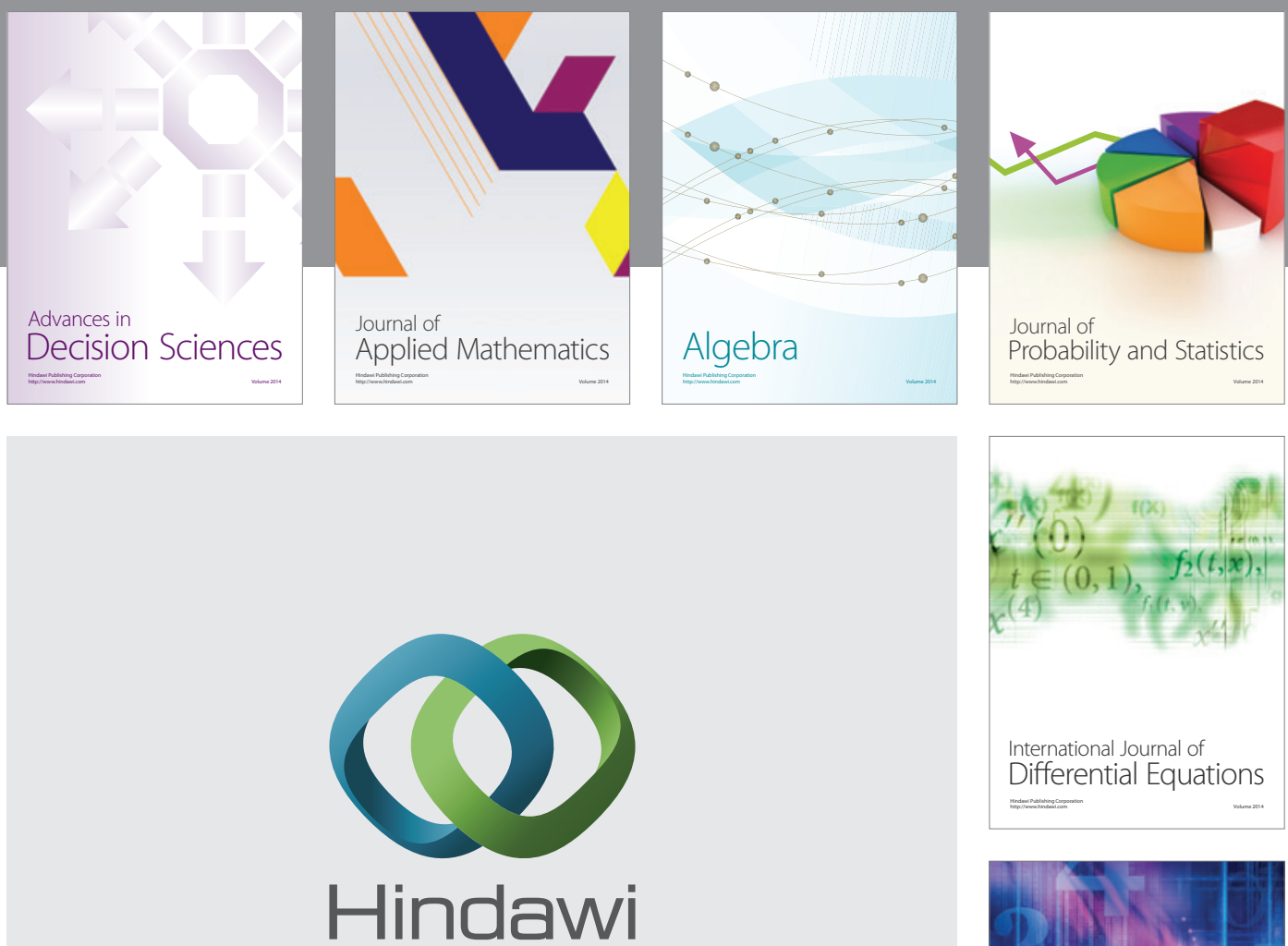

Submit your manuscripts at http://www.hindawi.com
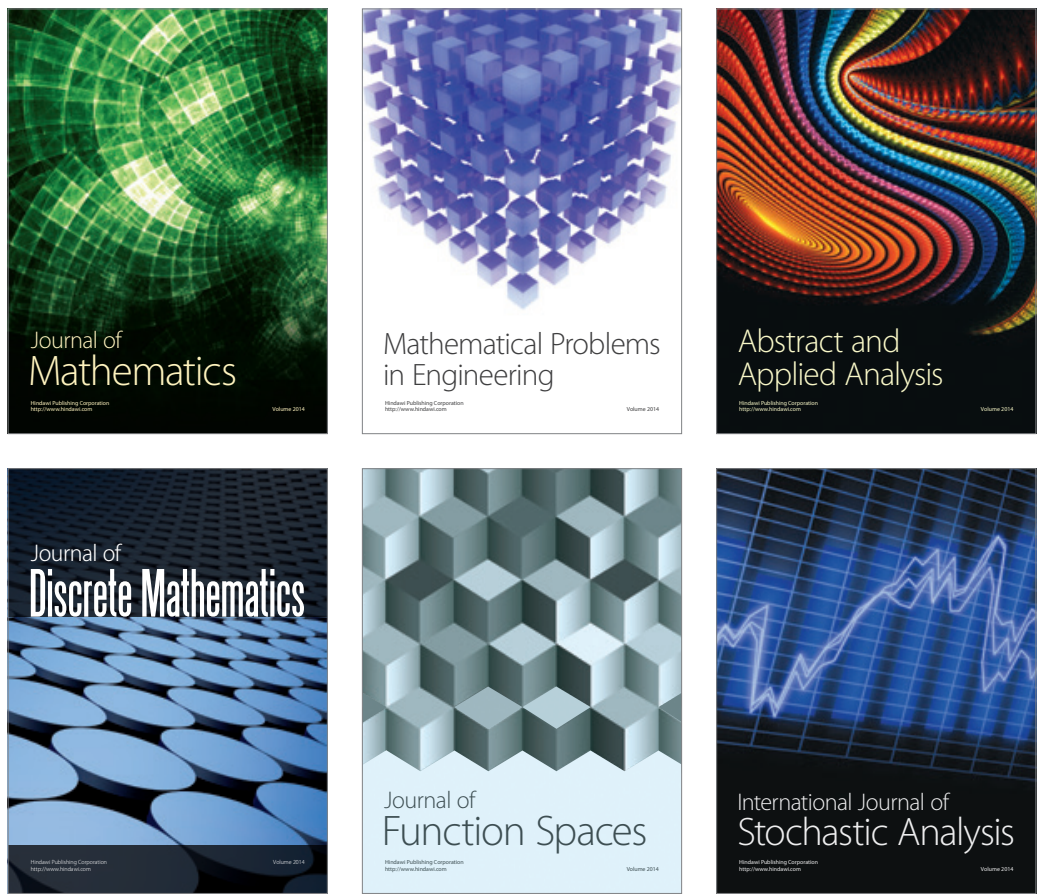

Journal of

Function Spaces

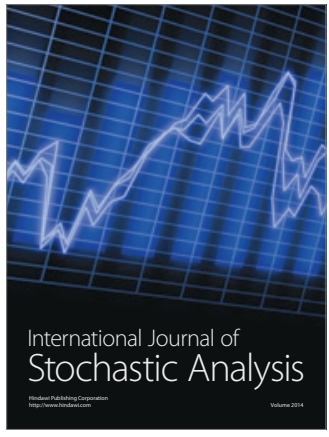

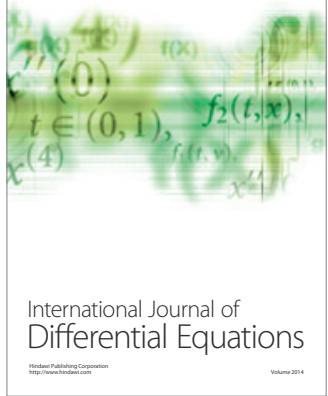
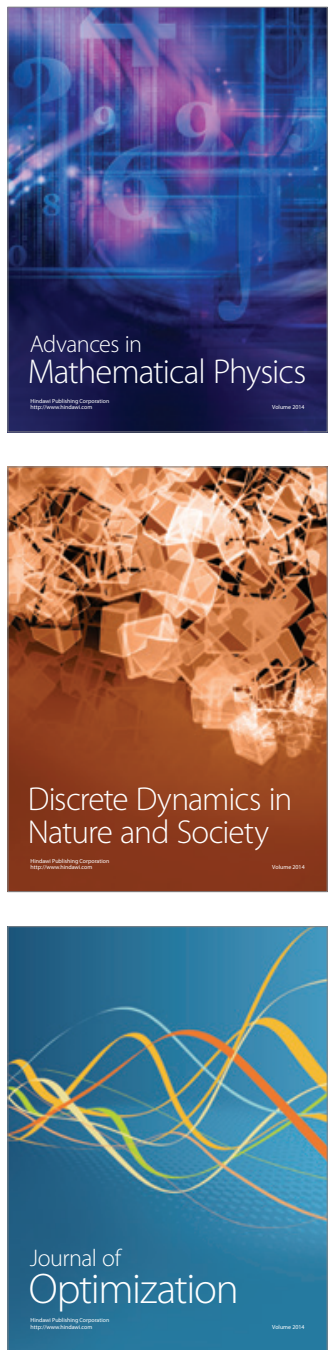